\title{
Effect chewing tapioca pearls in the bubble tea drinks on the salivary $\alpha$-amylase and phosphate level
}

\author{
Juni Handajani ${ }^{1 *}$, Dinda Kusumajati ${ }^{2}$, and Hania Fathiyah ${ }^{2}$ \\ ${ }^{1}$ Department of Oral Biology, Faculty of Dentistry, Universitas Gadjah Mada, Yogyakarta 55281, Indonesia \\ ${ }^{2}$ Dental Hygiene Study Program, Faculty of Dentistry, Universitas Gadjah Mada, Yogyakarta 55281, Indonesia
}

\begin{abstract}
Bubble tea drinks contained tapioca pearls, that can stimulate mastication. Chewing tapioca pearls may stimulate saliva production. Increased salivary secretion is thought to be correlated with an increase in inorganic components and salivary $\alpha$-amylase (SAA). This study aimed to evaluate the effect of bubble tea on SAA and salivary phosphate $\left(\mathrm{PO}_{4}^{3-}\right)$ levels.

Subjects were 15 people with a total sample of 60 . Each subject drank bubble tea with tapioca pearl for 3 days in the first week as the intervention group. In the second week the subjects drank tea without bubble for 3 days as a control group. Saliva samples were taken on day 1 before treatment and day 3 after treatment. Saliva was collected in the morning 09:00 am-12:00 pm for 1 minute. SAA levels were measured using an ELISA kit with Optical Density (OD) at $405 \mathrm{~nm}$. Phosphate levels were measured using a semi-quantitative test kit. Data were analyzed using ANOVA, Kruskal Wallis, t-test, and Pearson test $(\mathrm{p}<0.05)$.

The results of ANOVA and Kruskall-Wallis showed that there was a significant difference in the effect of consumption of bubble tea and tea without bubble $(\mathrm{p}<0.005)$ on SAA and phosphate levels. SAA and phosphate levels increased significantly after drinking bubble tea and tea without bubble $(\mathrm{p}<0.05)$. SAA levels after drinking bubble tea were significantly higher than after drinking tea without bubble. Comparison between phosphate levels after drinking bubble tea and tea without bubble were not significantly different $(p>0.05)$. Correlation between SAA and phosphate level was a significant different $(p<0.05)$ and $r$ was moderate category. It was concluded that the consumption of drinking bubble tea and tea without bubbles could increase salivary $\alpha$-amylase (SAA) also phosphate level and may improve quality of saliva through a salivary buffer mechanism.
\end{abstract}

Keywords: bubble tea, salivary $\alpha$-amylase (SAA), salivary phosphate $\left(\mathrm{PO}_{4}{ }^{3-}\right)$

\section{Introduction}

Saliva is as one of the body fluids that is important for maintaining oral health. Saliva has been known to have various functions including lubrication, helping the taste of food, moisturizing and protecting tissues in the oral cavity against infection and protecting teeth against abrasion. In addition, saliva also plays an important role in transporting food into the oesophagus, acting as a buffer, and maintain the water in the oral cavity. This protective function is strongly influenced by changes related to composition as well as viscosity, degree, ionic and protein composition [1].

Many stimuli can stimulate salivary secretion i.e., pain, mechanical, chemical, and neuronal stimuli; olfactory stimuli; seeing and thinking about food $[1,2]$. Chewing food is included as a mechanical stimulus while chemical stimulation can be in the form of tasting sweet, sour, salty, bitter and spicy foods. Neuronal stimuli are stimuli that come through the sympathetic and parasympathetic nerves. Pain from inflammation, gingivitis or an ill-fitting prosthesis can also stimulate salivary secretion. In addition, stress and psychological conditions are also things that affect salivary secretion [2].
One of the saliva contents is $\alpha$-amylase $(\alpha-1: 4$ glucan - 4-glucanohydrolase or ptyalin) which plays a role in the digestive system. High levels of salivary $\alpha$ amylase (SAA) are secreted by the parotid and submandibular glands, whereas from minor salivary glands and sublingual glands, the levels are low. This enzyme can break the $\alpha-1: 4$ bond between glucose molecules in amylose and amylopectin, as a component of starch. Salivary $\alpha$-amylase (SAA) levels will increase along with the increase in salivary flow rate [1]. In addition to these functions, SAA can bind to the Streptococcus group in the oral cavity, so that $\alpha$ amylase can function as a bacterial cleanser as well as a nutrient for bacteria. SAA is a component in the acquired enamel pellicle and acts as a receptor for bacterial adhesion to the tooth surface. The binding of SAA to bacteria and teeth has important implications in the formation of plaque and dental caries [3].

Calcium, phosphate and bicarbonate are the main inorganic components of saliva and involved in tooth protection, especially the remineralization and demineralization processes of teeth. High levels of salivary phosphate also affect the maturation and remineralization of teeth $[4,5]$.

\footnotetext{
*Corresponding author: junihandajani@ugm.ac.id
} 
Bubble tea drinks are currently very popular all over the world. This drink consists of tea mixed with a filling in the form of balls of tapioca pearls. Tapioca pearls are products made from sago starch [6,7]. Bubble tea drink is thought to stimulate masticatory stimulation during tapioca pearl mastication. Consumption of bubble tea may reduce salivary $\mathrm{pH}$ due to the breakdown of carbohydrates by SAA. Salivary phosphate has function to maintain salivary $\mathrm{pH}$ through a buffering mechanism and is thought to have a correlation with SAA. It is important to study the effects of chewing tapioca pearls to determine the possible risk factors for increasing caries due to decreased quality of saliva. This study aimed to evaluate the effect of bubble tea drinks on the levels of SAA and salivary phosphate $\left(\mathrm{PO}_{4}{ }^{3-}\right)$.

\section{Material and Methods}

Subject selection and collection of saliva samples followed the previous method by Handajani et al. [8]. Subjects aged 21-22 years. The study protocol was also approved by the Medical and Health Research Ethics Committee (MHREC), Faculty of Medicine, Public Health and Nursing, Universitas Gadjah Mada-DR. Sardjito General Hospital. Subjects who participated in this study signed an informed consent. During the Covid-19 pandemic, saliva sampling procedures followed health protocols.

\subsection{Measurement of salivary $\alpha$-amylase (SAA) and fosfat $/\left(\mathrm{PO}_{4}{ }^{3-}\right)$ level}

Salivary $\alpha$-amylase (SAA) and fosfat level were assessed in Parasitology Laboratory, Faculty of Medicine, Public Health and Nursing, Universitas Gadjah Mada. Measurement SAA was done according to protocol from ELISA kit (Salimetric LLC, California, USA). Saliva samples were taken from the freezer at $20^{\circ} \mathrm{C}$ and then thawed at room temperature. Saliva was vortexed and centrifuged at $1500 \mathrm{x}$ g for 15 minutes. The clear part was taken using a pipette and put into a tube that has been labeled. The plate reader was set up for incubation at $37^{\circ} \mathrm{C}$ with a wavelength of $405 \mathrm{~nm}$. Substrate of $\alpha$-amylase was heated to $37^{\circ} \mathrm{C}$. Saliva samples were diluted using $\alpha$-amylase Diluent in a ratio of $1: 10$ or $10 \mu \mathrm{l}$ of saliva was added to $90 \mu \mathrm{l}$ of $\alpha$ amylase Diluent. Then it was diluted again by adding 10 $\mu 1$ of saliva to $190 \mu 1$ of $\alpha$-amylase Diluent (1:20) and the final dilution was 1:200. Saliva samples, high and low control were put into 96 wells according to the design of $8 \mu \mathrm{l}$ each. In each well, $320 \mu 1$ of $\alpha$-amylase substrate was added which had been heated to $37^{\circ} \mathrm{C}$. Samples were read at a wavelength of $405 \mathrm{~nm}$ and $\alpha$ amylase level was in $\mathrm{U} / \mathrm{ml}$.

Salivary phosphate $\left(\mathrm{PO}_{4}{ }^{3-}\right)$ level was measured using phosphate test kit according to manufacturer's protocol (QUANTOFIX ${ }^{\circledR}$ Phosphate, catalog No.91320, Macherey-Nagel GmbH \& Co.KG, Germany). Saliva was put in a tube for the $1^{\text {st }}$ test (test tube) as much as $5 \mathrm{~mL}$ then added 5 drops of $\mathrm{PO}_{4}{ }^{3-}-1$ (nitric acid). The test tube was shake carefully to mix the saliva with nitric acid. The $2^{\text {nd }}$ test tube was placed in a thermoformed mold and added 6 drops of $\mathrm{PO}_{4}{ }^{3-}-2$. Test strip was inserted into the test tube containing the saliva sample for 15 seconds and shaken off excess liquid. Then test strip was inserted into the $2^{\text {nd }}$ test tube for 15 seconds and shaken the excess liquid. The test strip was waited for 60 seconds, then test strip was compared with the color scale according to the kit. Salivary phosphate levels were in $\mathrm{mg} / \mathrm{L}$.

\subsection{Data Analysis}

Statistical measurement (IBM SPSS v22) was used to analyze data of SAA and salivary phosphate $\left(\mathrm{PO}_{4}{ }^{3-}\right)$. Data were calculated using Shapiro-Wilk and Levene's test to evaluate if the data normal and homogenous. Data SAA level were measured using ANOVA and Post hoc Games-Howell while phosphate level was done using Kruskall-Wallis and Mann-Whitney.

\section{Result}

According to health protocol, all participants were not reactive to rapid test Covid-19, had good OHI-S, no smoking, no history dry mouth and no history systemic disease. The results of measuring levels of SAA and salivary phosphate before and after drinking bubble tea or tea without bubbles were described in Figure 1.

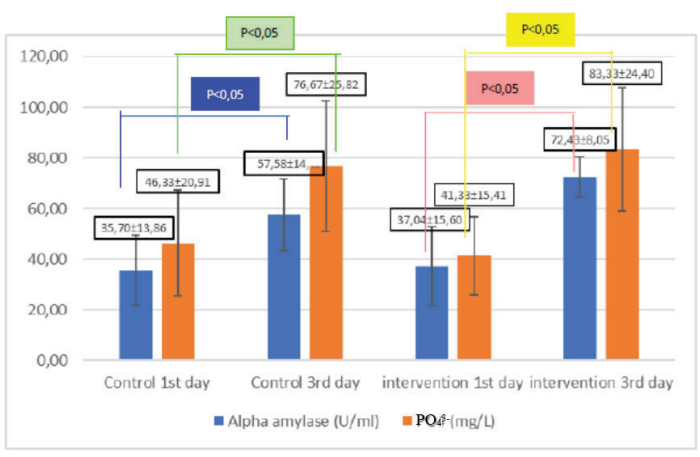

Fig 1. Salivary $\alpha$-amylase $(\mathrm{U} / \mathrm{mL})$ and phosphate $(\mathrm{mg} / \mathrm{L})$ levels increased on $3^{\text {rd }}$ day after drinking bubble tea (intervention group) and tea without bubble (control)

The results showed an increase in SAA and salivary phosphate levels on the $3^{\text {rd }}$ day after drinking bubble tea (intervention group) and tea without bubble (control). The normality data of SAA level were calculated using Shapiro-Wilk and showed the significance was $\mathrm{p}>0.05$ while phosphate levels was $\mathrm{p}<0.05$. The homogeneity calculation showed that both SAA and phosphate levels were $p<0.05$. The results assumed that the SAA levels were normal but not homogeneous, while the data of salivary phosphate levels weren't normal and not homogeneous. Subsequent data analysis on SAA was carried out by parametric ANOVA test with Post hoc Games-Howell while phosphate levels were carried out by nonparametric Kruskall-Wallis and Mann-Whitney tests. The result of ANOVA and Kruskall-Wallis test were described in Table 1. 
Table 1. The result of Anova test for SAA level and KruskallWallis test for salivary phosphate

\begin{tabular}{lcc}
\hline \multicolumn{1}{c}{ Variabel } & Statistic test & $\mathrm{p}$ \\
\hline Salivary $\alpha$-amylase (SAA) & ANOVA & 0.000 \\
Salivary phosphate & Kruskall-Wallis & 0.000 \\
\hline
\end{tabular}

Table 1 showed the effect of drinking bubble tea drinks significantly increases salivary $\alpha$-amylase (SAA) and phosphate levels. To determine the effect of each drinking bubble tea and tea without bubble, followed by Post hoc Games-Howell and Mann-Whitney tests as shown in Table 2 and Table 3.

Table 2. Statistic result of Post hoc Games-Howell for salivary $\alpha$-amylase (SAA)

\begin{tabular}{lcccc}
\hline \multicolumn{1}{c}{ Group } & $\begin{array}{c}\text { Control } \\
1^{\text {st }} \text { day }\end{array}$ & $\begin{array}{c}\text { Control } \\
3^{\text {rd }} \text { day }\end{array}$ & $\begin{array}{c}\text { Intervention } \\
1^{\text {st }} \text { day }\end{array}$ & $\begin{array}{c}\text { Intervention } \\
3^{\text {rd }} \text { day }\end{array}$ \\
\hline $\begin{array}{l}\text { Control 1 } \\
\text { day }\end{array}$ & - & 0.001 & 0.995 & 0.000 \\
$\begin{array}{l}\text { Control } 3^{\text {rd }} \\
\text { day }\end{array}$ & - & - & 0.004 & 0.010 \\
$\begin{array}{l}\text { Intervention } \\
1^{\text {st }} \text { day }\end{array}$ & - & - & - & 0.000 \\
$\begin{array}{l}\text { Intervention } \\
3^{\text {rd }} \text { day }\end{array}$ & - & - & - & - \\
\hline
\end{tabular}

Table 2 described the comparison of SAA levels after drinking bubble tea (intervention group) and drinking tea without bubble (control) were a significant increase $(\mathrm{p}<0.05)$. The comparison was not significant $(p>0.05)$ in the control group with the intervention on $1^{\text {st }}$ day. The results indicated that the levels of SAA same in the group before drinking bubble tea and drinking tea without bubble.

Table 3. Statistic result of Mann-Whitney test for salivary phosphate

\begin{tabular}{lcccc}
\hline \multicolumn{1}{c}{ Group } & $\begin{array}{c}\text { Control } \\
1^{\text {st }} \text { day }\end{array}$ & $\begin{array}{c}\text { Control } \\
3^{\text {rd }} \text { day }\end{array}$ & $\begin{array}{c}\text { Intervention } \\
1^{\text {st }} \text { day }\end{array}$ & $\begin{array}{c}\text { Intervention } \\
3^{\text {rd }} \text { day }\end{array}$ \\
\hline $\begin{array}{l}\text { Control } 1^{\text {st }} \\
\text { day }\end{array}$ & - & 0.003 & 0.552 & 0.001 \\
$\begin{array}{l}\text { Control } 3^{\text {rd }} \\
\text { day }\end{array}$ & - & - & 0.000 & 0.464 \\
$\begin{array}{l}\text { Intervention } \\
1^{\text {st day }}\end{array}$ & - & - & - & 0.000 \\
$\begin{array}{l}\text { Intervention } \\
3^{\text {rd day }}\end{array}$ & - & - & - & - \\
\hline
\end{tabular}

Results from Table 3 showed that phosphate levels increased significantly $(\mathrm{p}<0.05)$ after drinking bubble tea (intervention group) and tea without bubble (control) as compared to the control and intervention on $1^{\text {st }}$ day compared to $3^{\text {rd }}$ day. The comparison was not significant $(p>0.05)$ on $1^{\text {st }}$ day of the control and intervention groups, it can be assumed that the phosphate levels at the beginning of the treatment were the same. The comparison was not significant on the $3^{\text {rd }}$ day of the control group with the intervention group indicating that the increase in phosphate levels after drinking bubble tea and tea without bubble tea was the same although from Figure 1 it can be seen that the phosphate level on $3^{\text {rd }}$ day of the intervention group was higher than the control but not statistically significant.

Table 4. The result of Pearson Correlation between SAA level and salivary phosphate

\begin{tabular}{lccc}
\hline \multicolumn{1}{c}{ Variabel } & Statistic test & $\mathrm{p}$ & $\mathrm{r}$ \\
\hline $\begin{array}{l}\text { Salivary } \alpha \text {-amylase } \\
\text { (SAA) }\end{array}$ & Pearson & 0.000 & $0,451^{* *}$ \\
Salivary phosphate & & & \\
\hline
\end{tabular}

Pearson correlation between SAA level and salivary phosphate showed a significant different $(\mathrm{p}<0,05)$ even though $r$ belongs to the moderate category $(r=0,451)$.

\section{Discussion}

The results showed an increase in SAA and salivary phosphate levels on the $3^{\text {rd }}$ day after drinking bubble tea (intervention group) and tea without bubble (control). The mechanism of increasing SAA and salivary phosphate levels was thought to be related to an increase in saliva volume and $\mathrm{pH}$ after consuming tapioca pearls contained in bubble tea and after drinking tea without bubbles according to the study from Kusumajati et al. [9] Consumption of tapioca pearls in bubble tea may stimulate salivary secretion through the sensation of chewing tapioca pearls which were supple and soft. In the consumption of bubble tea, two stimuli may occured simultaneously, namely chemical and mechanical stimuli. Chemical stimulation through the perception of the taste of sweetness from bubble tea drinks and mechanical stimuli arised from chewing tapioca pearls. Consumption of tea without bubbles may only stimulate the chemical.

The mechanical and chemical stimuli of mastication may affected the action of the sympathetic and parasympathetic nerves. The major salivary glands, which consist of the parotid, submandibular, and sublingual glands, were innervated by the sympathetic nerves. The parasympathetic nerves innervate the major and minor salivary glands on the palate. The innervation of the parasympathetic nerves affected the secretion of saliva, namely the volume of saliva produced by secretory cells. The saliva produced in this study belongs to the category of whole saliva which was produced from all major and minor salivary glands. Salivary secretion from the parotid gland produced liquid saliva, while the saliva from the submandibular and sublingual glands and the minor salivary glands was mucus because of the glycoprotein content [10].

Stimulation of mastication and sweetness (taste) of bubble tea and tea without bubbles was thought to stimulate the tongue and the surrounding area through parasympathetic nerve impulses in the afferent limb in the salivary reflex that runs through the glossopharyngeal (CN IX), facial (CN VII) nerves, vagal (CN X) (taste) and trigeminal (CN V) (chewing). Parasympathetic nerve stimulation were also increase blood flow to the salivary glands so that it was increase the supply of nutrients [10]. Mechanical mastication was a functional unit between blood circulation, nerves, masticatory muscles, temporomandibular joints, and teeth will stimulate autonomic nerves for salivary 
secretion [11] so that during the chewing process there was contraction of the masticatory muscles to increase salivary secretion.

The results of the study in Table 2 showed that SAA levels increased significantly on the $1^{\text {st }}$ day comparison with the $3^{\text {rd }}$ day after consumption of bubble tea and tea without bubble. The results were also significantly different in SAA levels on the $3^{\text {rd }}$ day after consuming bubble tea and tea without bubble tea. The increase in SAA consumption of bubble tea and tea without bubbles may be due to the masticatory and chemical stimulation of the sweet taste which were stimulated the secretion of the parotid gland. About $80 \%$ of SAA was produced from the parotid gland, the rest comes from the submandibular gland [10]. Another mechanism was chewing and chemical stimulation of bubble tea consumption and tea without bubbles could stimulate sympathetic nerve activity which cause acinar cells release macromolecules including $\alpha$-amylase [10].

The results from Aminabadi et al. [12] suggested that an increase in salivary flow rate affected the increase in salivary $\mathrm{pH}$ due to an increase in salivary buffer capacity. The buffering capacity of saliva was influenced by components, especially bicarbonate, phosphate, urea, amphoteric proteins, and enzymes [13]. In this study, phosphate levels increased after consumption of bubble tea and tea without bubble. The highest phosphate level was obtained after consuming bubble tea of $83.33 \mathrm{mg} / \mathrm{L}$ (Figure 1), then after drinking tea without bubble $76.67 \mathrm{mg} / \mathrm{L}$. If the salivary phosphate level was converted to $0.877 \mathrm{mmol} / \mathrm{L}$ (bubble tea) and $0.807 \mathrm{mmol} / \mathrm{L}$ (tea without bubble). This result was still low compared to the reference of Edgar et al. [10] who stated that the stimulated salivary phosphate level was $5.69 \mathrm{mmol} / \mathrm{L}$ and $2.70 \mathrm{mmol} / \mathrm{L}$ unstimulated although the results of this phosphate level were significantly higher than the phosphate level before drinking bubble tea or tea without bubble tea. The low level of phosphate from the results of this study compared to the reference may be due to limitations in sampling because during the Covid-19 pandemic, saliva samples were taken by the subject themself, the researcher could only gave instructions from a far.

Table 3 showed insignificant results on the $3^{\text {rd }}$ day of phosphate levels after consumption of bubble tea and tea without bubble but significant results on the comparison of $1^{\text {st }}$ day and $3^{\text {rd }}$ day. These results indicated that the effects of both bubble tea and nonbubble tea could increase phosphate levels, which were not significantly different on $3^{\text {rd }}$ day. This result is in line with previous study that Calcium (Ca) levels increased significantly after consumption of bubble tea drinks on the $3^{\text {rd }}$ day, while the results were not significant after consumption of tea without bubbles [8]. These results were consistent with previous studies that $\mathrm{Ca}$ and phosphate are in line with their important role in oral homeostasis, especially for teeth. In the process of releasing phosphate from acinar cells, it was known that the concentration is low and then there was a modification of the saliva content through the ductus. Increased levels of phosphate in saliva were thought to be due to phosphate translocation involving transepithelial active transport. The phosphate level across the basolateral membrane was characterized by a $\mathrm{Na}+$ dependent phosphate transporter known as NPT2b [10]. This study still needs to be continued to reveal whether bubble tea plays a role in NPT2b as a phosphate transporter.

Correlation between SAA and salivary phosphate showed a significant different (Table 4). The result proved that the increase SAA level was in line with the increase salivary phosphate even though the correlation was in the moderate category. The increase in SAA played a rôle in breaking down the carbohydrates in bubble tea. Consumption of bubble tea containing carbohydrate was thought to reduce salivary $\mathrm{pH}$. When the salivary $\mathrm{pH}$ becomes very acidic, the phosphate ion was immediately converted into $\mathrm{HPO}_{4}{ }^{2-}$ and then $\mathrm{H}_{2} \mathrm{PO}^{4-}$ which will act as one of the salivary buffers [14, 15]. Consumption bubble tea drinks may improve saliva quality through a salivary buffer mechanism as indicated by an increase in salivary phosphate along with an increase in SAA.

\section{Conclusion}

Based on our data, we concluded that consumption of bubble tea and tea without bubbles could increase salivary $\alpha$-amylase (SAA) and phosphate level. SAA levels after drinking bubble tea were significantly higher than after drinking tea without bubble. Salivary phosphate levels after drinking bubble tea and tea without bubble were not significantly different. Chewing tapioca pearls in bubble tea drinks may improve quality of saliva through a salivary buffer mechanism.

\section{Grant information}

This research was supported by Dana Masyarakat Faculty of Dentistry Universitas Gadjah Mada (Contract No. 3636/UN1/FKG1/Set.KG1/LT/2020).

\section{Acknowledgement}

We would like to thank to Mrs. Rumbiwati, ST., M.Sc as staff in Parasitology Laboratorium, Faculty of Medicine, Public Health and Nursing, Universitas Gadjah Mada.

\section{Conflict of interest}

The authors declared that they have no conflict of interest related to this publication.

\section{References}

1. A. Sarkar, F. Xu, S. Lee. Human saliva and model saliva at bulk to adsorbed phases-similarities and differences. Advances in Colloid and Science $\mathbf{2 7 3}$ (2019). https://doi.org/10.1016/i.cis.2019.102034

2. P.A. Nuttall . Wonders of tick saliva. Ticks Tick Borne Dis. $\mathbf{1 0}$ (2019). DOI: 10.1016/j.ttbdis.2018.11.005

3. F.A. Scannapieco, G. Torres, M.J. Levine. Salivary alpha-amylase: role in dental plaque and caries formation. Crit Rev Oral Biol Med. 4 (1993). doi: 10.1177/10454411930040030701. PMID: 8373987.

4. S.P. Humphrey, R.T. Williamson. A Review of 
Saliva: Normal Composition, Flow, and Function, JPD. 85 (2001). DOI: $10.1067 / \mathrm{mpr} .2001 .113778$

5. A.M.L. Pedersen AML. Saliva. Copenhagen: Zendium (2007)

6. V.F. Pangkey, S.L.H.V.J. Lapian, F. Tumewu. The Analytical Hierarchy Process (AHP) Of Consumer Purchase Decision in Selecting Bubble Tea Shop. Jurnal EMBA 4 (2016).

7. C.S. Lin, C.J. Yang, P.J. Chen, K.W. Liu, H.P. Lin, C.C. Lin, Y.C. Lee, W.C. Cheng, C.I. Wei, Y.H. Tsai. Assessment of Microbiological and Chemical Quality of Bubble Tea Beverages Vended in Taiwan. JFP 82 (2019). DOI: 10.4315/0362-028X.JFP-18$\underline{517}$

8. J. Handajani, D. Kusumajati, H. Fathiyah, R.T.C. Tandelilin, H. Susilowati. Quality improvement of saliva by chewing tapioca pearls in bubble tea drinks: a randomized experimental trial. F1000Research $\quad \mathbf{1 0} \quad$ (2021) https://doi.org/10.12688/f1000research.28028.1

9. D. Kusumajati, J. Handajani, H. Susilowati. The effect of chewing tapioca pearls on bubble milk tea on the degree of acidity $(\mathrm{pH})$ and volume of saliva. Thesis. (2021).

10. Edgar M, Dawes C, O’Mullane D. Saliva and Oral Health, $4^{\text {th }}$ Ed. Ireland: Stephen Hancoocks Limited Publ. (2012).

11. L.K. Rezky, J. Handajani. The effect of chewing gum on salivary status. Maj Ked Gi 18 (2011). http://i-

lib.ugm.ac.id/jurnal/detail.php?dataId=11664

12. N.A. Aminabadi, E. Najafpour, Z. Razavi Rohani, A. Sighari Deljavan, M. Ghojazadeh, Z. Jamali. Linear reciprocal interaction between dental caries and salivary characteristics. J Oral Sci. 55 (2013). doi: 10.2334/josnusd.55.337. PMID: 24351922

13. E.Z. Bilbilova, A.S. Ivkovska, Z. Georgiev, E. Stefanovska. Evaluation of buffer capacity of saliva in caries-free and caries-active children. Sec Med Sci. 1 (2013).

14. P. Anderson, M.P. Hector, M.A. Rampersad. Critical $\mathrm{pH}$ in resting and stimulated whole saliva in groups of children and adults. Int J Pediatr Dent. 11 (2001)

15. A.R. Prabhakar, A.B. Shubha, T. Mahantesh, Estimation of Calcium, Phosphate and Alpha Amylase Concentrations in Stimulated Whole Saliva of Children with Different Caries Status: A Comparative Study. MJD. 29 (2008). 